„Etnografia Polska”, t. LXIV, 2020, z. 1-2

PL ISSN 0071-1861; e-ISSN: 2719-6534

DOI: $10.23858 / \mathrm{EP} 64.2020 .009$

CC BY 4.0

ALINA KACZMAREK-SUBRAMANIAN

Institute of Archeology and Ethnology, Polish Academy of Sciences, Warsaw

\title{
CASTE AND ETHNICITY IN SOUTH INDIA: A CASE STUDY OF THE KONKANI PEOPLE IN KOCHI
}

\section{INTRODUCTION}

This article attempts to present the problem of caste in the 2010s as a part of contemporary transformations and related issues based on the findings of important sociological and anthropological studies (ethnic awareness of caste, Barnett 1975; ethnicization of caste, Fuller 1996; caste as social group and social practice, Natrajan 2005, 2012a, 2012b; performative and changing phenomenon, Reddy 2005). It focuses on a case study of the Konkani people who inhabit the city of Kochi in southern India ${ }^{1}$. Kochi lies within the district of Ernakulam in the state of Kerala. Cochin $^{2}$ is the post-British name of the city, while the current official name is Kochi. The source of information herein presented on the Konkani in $\mathrm{Kochi}^{3}$ is that of fifty in-depth ethnographic interviews, field notes, and other materials - along with experiences from participant observations arising from field research I was conducting in 2014-2018. My interlocutors had Konkani origin and spoke more or less Konkani language. I conducted interviews in the homes of the respondents, with a few exceptions, as when they were conducted at the interlocutor's workplace, at school, in a shop, or institution. My friend, a member of the caste named Goud Saraswat (who will be described further), often helped me find interlocutors. I found some of them also by accident, while talking to the inhabitants of Kochi and finding out who knows the Konkani language, although the language we spoke was the language of education and administration in Kerala, which is English. Some of the interviewees belonged to the group of activists for the Konkani language and I often

1 This research was completed thanks to financing under the IAE PAN competition Adulescentia Est Tempus Discendi and under the National Science Centre competition Preludium (research project UMO-2016/21/N/HS3/03171 entitled Contemporary social transformations in India based on the example of the strategy of maintenance and building of a multi-layer identity by Konkani castes in Kochi, scheduled for the years 2017-2019).

2 The name of the city takes various forms in the literature, including Kochi and Cochin. In this text I use the form Kochi.

${ }^{3}$ Most of them live in Mattancherry, with the neighbouring part called Fort Kochi being the oldest part of the city. 
met them at related events - book promotions, an unveiling of a monument, and seminars and conferences on the language and the Konkani group. All interviewees had completed primary education, most of them had gone to high school, and many of them were also college or university graduates ${ }^{4}$. Members of the poorest caste - the Kudumbi - were also educated people. What greatly facilitated my research and made it a pleasure were the interviewees and the whole community's interest in the work I was doing. Not only did the interlocutors met with me willingly and provide broad answers (the average interview lasted at least an hour and a half), but I also sensed that they felt appreciated with someone taking an interest in their knowledge and insights. The only problem that arose during my research, and one which I could not completely avoid, related to the gender of the interviewees. For the most part, they were middle-aged or older men. Apart from the few interviews with women only, most of the conversations in which women participated were interviews of several people, often with the whole family. Unfortunately, many times a woman asked for an interview refused, saying that her husband, grandfather, or father-in-law would be able to give a more competent answer.

\section{THE RESEARCH PROBLEM}

Especially interesting and worth investigating is the question: how in a democratic state, whose caste system was officially abolished in 1947, does the caste situation look today? Most researchers (Dirks 2002; Natrajan 2005) underline that changes in social life and that the former caste borders have disappeared in modern India. Today the lingering traces of this social practice can be found in niches (Natrajan 2012a, 2012b) such as remote village areas, small groups living far away from their homelands and forming a kind of diaspora. From my ethnographic research I come to the conclusion that outlines of the caste system can still be found, though in the new guise. One of the niches where elements of the caste system operate is the Konkani community in the urban environment of Kochi. The issue of interest to me is the current way of cultivating caste in the reality of a democratic state - over 70 years since its abolition - where the traditional caste system interweaves with broader national, ethnic, educational, and economic awarenesses, which are of an entirely different nature. Such the case I decided to undertake research on the identity of the Konkani group, consisting of five castes. It quickly turned out that in order to discuss cultural features like the customs, religion, language, and social practices of representatives of this group, I could not limit myself to single categories of caste, ethnicity, or language. Undertaking research on merely a single caste would lead to misunderstanding, because of the broader identification related to the language and place of origin (Goa) that is superimposed on the caste identity.

${ }^{4}$ The level of education in Kerala is very high, and literacy has already officially reached the level of one hundred percent, which is a great achievement compared to the rest of the Indian states. 
Konkani identification strategies in Kochi have become a leitmotiv in my research. I sought to find out what the Konkani identify with and in what life situations, including everyday life, as well as in unusual and festive times, when one identification prevails over another. After some time, a picture of a multi-layered identity emerged, in which the sense of belonging has many dimensions that coexist with each other. Depending on the social context, some of the identifications may be more visible - and some less so. I wanted to learn more about the strategy of maintaining caste identity and building a new, more modern and convenient identity in a democratic state where identities, though based on equality, emphasize ethnic belonging based on tradition, language, and common place of origin. I became interested in what is happening to the existing community as a result of these changes, and how the Konkani operate in what I call a multilayered identity.

Observations in the field raised reflections and questions on whether the foundations of the formation of the Konkani group were based on the influence of a modern state, on the collective will to emancipate members of this group, or whether the significance of primordial bonds is given by people themselves (cf. Geertz 1973). It seems that both forces are acting simultaneously, and that this can be seen as a trace of pre-colonial power relations.

Firstly, I am going to present a short description of the Konkani people, and further, based on a case study, I will elaborate on the above topic of Konkani identity.

\section{THE KONKANI}

When starting my research on the Konkani it was impossible to bypass old precolonial power relations. The same caste system was in force throughout India, but in practice there were differences depending on the region, so it is worth analyzing a specific case. When looking at the map of the Indian Peninsula, one finds the city of Kochi on its southwestern-most tip. The thin strip of the Malabar Coast is the contemporary state of Kerala, delimited following India's gaining of independence in 1947 based on the linguistic criterion. The majority language spoken in this region is Malayalam, a Dravidian language. The Indian social system based on units such as varnas or castes ${ }^{5}$ did not emerge in Kerala until relatively late. It is dated somewhere after the $11^{\text {th }}$ century, after Namboodiri Brahmins ${ }^{6}$ had well settled in this land of Tamil tribes (Sadasivan 2000, p. 302). Mysore N. Srinivas believes that the ancient varna system, which most likely emerged as a result of Indian tribes being conquered by Aryans, may be deemed a pan-Indian phenomenon, present in the entire sub-continent (1952, p. 219). It consists of four major social classes. These are the Brahmins - warriors and kings; the Vaishyas - merchants; and Shudras - the working class, on the margins of which there exists the group of Pariahs, excluded

\footnotetext{
${ }^{5}$ Varna is the name of the four social states, and caste as a professional group.

${ }^{6}$ Namboodiri Brahmins is the native caste dominating in the lands of the state of Kerala.
} 
both from the class system and socially, the so-called untouchables. Nevertheless, Pauline Kolenda underscores that in the south of India, the distribution of the castevarna system has always been different from the northern Indian model. Based on sources and knowledge of the various caste theories, she maintains that originally not only the class of Vaishyas was missing in Kerala, but also (significantly) the class of Kshatriyas, the warriors. People responsible for the typically roles of Kshatriyas in Kerala were classified as Shudras. Thus, in southern India it is more precise to speak of Brahmins, non-Brahmins, and untouchables, alternatively referred to as AdiDravida, the original inhabitants of India (Kolenda 1985, p. 95). In my research this idea seems also to be confirmed:

When the Brahmins came they brought the four-systems like the four different levels, castes - like Brahmin, Kshatriya, like that. Before that, that system wasn't here in Kerala (Vaishya Vani, 10.11.2014, Kochi, male, 35).

From today's point of view, we would talk about various forms of solidarity (Appadurai 2009, p. 31). In comparison to varna, caste is a much smaller unit that functions all over India regionally, characterized by specific regulations that apply to its members, such as endogamy and the choice of profession, although in modern times, this last tradition is frequently abandoned. Caste within the context of the caste system is a unit that fulfills a determined social role, integrated in the local and traditional system of interdependencies, exchange of services and hierarchy, whose place within society is dictated by determinants of ritual purity. A caste may, but does not have to cultivate a separate, distinct culture (ibidem, p. 9).

Since the local variation of the caste system has never featured the socio-mythical class (varna) of the Vaishyas, who were originally merchants, this affected the cultural variety in Kochi. Over the centuries, people of distinct origins came to live here. Migrations were often a result of religious persecutions, such as in the case of the Konkani or Jews, but they were also at times connected to the strategic trade location of Kochi, as in the case of merchants who relocated from Gujarat. The majority of groups who settled in Kochi traded in spices and other goods. Moreover, Kochi was the first Indian colony where representatives of the authorities resided; first the Portuguese, then the Dutch, and finally the British (cf. Bernard 2015). All these factors made for a unique environment in terms of diverse origins, the configuration of religious groups (Hindu, Christian, and Muslim), the presence of many languages besides the local (and now official) Malayalam. Thus, unique systems of values, customs, and castes from other regions of India were adapted to the new place.

The Konkani who inhabit Kochi are Hindus who originate from the Konkan region in Goa and who speak among each other a local language from that region, IndoEuropean Konkani (of the southern Indo-Aryan language group). It is their first language, used only at home and with other Konkani members. The Konkani arrived in Kochi, where Malayalam is spoken, in the $16^{\text {th }}$ century, when they escaped the Portuguese authorities and their aggressive missionary politics pursued in Goa (cf. Bernard 2015). The city's strategic port was divided into Fort Kochi, which belonged 
to the colonial authorities, and into a part that remained under the jurisdiction of the local Raja of Mattancherry. It was there the Konkani, as well as many other groups of diverse backgrounds, settled. Here, thanks to their cooperation with the local raja, this Hindu group was able to maintain its religious autonomy. A similar policy was also applied to other religious groups in the Rajas' jurisdiction, including the Jews, Muslims, and other Hindu subcastes ${ }^{7}$. The Konkani's poignant history in his regard has not to date been covered by in-depth anthropological study.

Five caste communities speak Konkani in Kochi. Besides language and a common place of origin, they are also embraced by Hindu beliefs, shared rituals, and the importance ascribed to individual gods. Twenty-two families the Goud Saraswat Brahmins are appointed by the community to handle priestly duties, while the rest of the community traditionally makes a living in trade. The latter is the Vaishya Vani community, who are also customarily merchants. The Saraswat are responsible for the upkeep of temples and for the cultivation of the temple dance tradition referred to as devadasi. Sonar, or the caste of goldsmiths, are alternatively called the Daivadnya Brahmins. The Kudumbi make up the agricultural caste ${ }^{8}$. The mutual relations between these communities have changed over time. For example, regarding Vaishya Vani and Goud Saraswat Brahmins, the scenario in the shared memory is that, in the past, these communities were bound together by an exchange of services in the Konkan region and arrived from Goa together, but began to function separately once in Kerala. From the interviews I conducted it follows that a conflict erupted here. Vaishya Vani share the memory of conflict and distrust arising from the past power relationships. In conversations with my interviewees there were recurring mentions that in the distant past, in the $16^{\text {th }}$ century, the Vaishya Vani merchants held the key to a shared temple that had been built by various Konkani castes working in collaboration. As a result of the conflict mentioned, the crux of which is not clear (the interlocutors chose either not to divulge this information or did not know it, as per their declarations it may have happened around the $18^{\text {th }}$ century), the paths of the castes originating from Goa parted, and the traditional inter-caste system of service exchange was disrupted. During my fieldwork, I observed that the Goud Saraswat Brahmins remained a relatively insular community concentrated around the Thirumala Devaswom temple, where within this community we can find much fewer mixed marriages and less mingling with other groups. Despite the vicinity and many shared features with the Vaishya Vani merchants, the temple rituals of the latter are celebrated by Tulu Brahmins of Maharashtra, perhaps owing to their lower status within the caste hierarchy. According to all informants, following India's gaining of independence in 1947, a small group of the Saraswat decided to pursue education, and its members are often renown artists, musicians, and professors. The Sonar

\footnotetext{
${ }^{7}$ In addition to caste as professional groups, there were also groups of the same caste, but associated with a separate territory, and thus - language.

${ }^{8}$ Information about the history of the Konkani group comes from ethnographic interviews conducted in the field and from local literature. Cf.: Divakar 2013; Mllaya 2016.
} 
Konkani are still concentrated around their own temple, but they have abandoned their traditional profession of goldsmithing and currently make their living in other ways, ones typical of the middle class, such as office work or small businesses.

Here only 35 families... [...] Now everyone is well-educated (Sonar, 27.12.2015, Kochi, male, 60).

The Kudumbi, in turn, according to my interviewees, have assimilated most fully, adopting many elements of the local lifestyle, such as food, celebration of the Kerala holiday of Onam, and speaking mostly Malayalam, also among each other. In total, the group of all Konkani language users in the area of interest to me has less than 50 thousand members. The dynamics of interactions between the representatives of individual communities vary, and these relations play out mostly in everyday life. The scale of cultural similarities between these communities also varies, especially as concerns the variety of Konkani language spoken. Each sub-group uses somewhat different words and grammatical forms. All, however, are now under the tremendous influence of the local Malayalam language, which is of significance within the context of measures pursued by Konkani activists who pursue the harmonization of Konkani language and to re-establish relations with Goa. What binds the Kochi Konkani today is first and foremost the remembrance of their place of origin, the attachment to it, and the experience of migration itself, which left a lasting mark on the collective memory, as well as their native Konkani language, used by all five communities to communicate both at home and outside home between Konkani communalities. They even call themselves collectively Konkani-speaking people, beyond the caste differentiations. Nowadays, the Kerala Konkani use these representative components of their identity in their activities aiming to underscore the cultural and linguistic heritage of their group, setting them apart from the rest of the multi-cultural city of Kochi. Beyond Konkani language they underline differences in food habits, the ritual year, and the history that has marked their identity.

\section{WHAT IS CASTE? THE PRESENT VERSUS THE PAST}

Pre-existing concepts of difference are re-expressed. New categories have been added to old ones, a process which seems to be an example of a developing heritage. The caste system was a very generalizing concept. Contemporary examples testify not to a single caste system definition which could be applied in all of India; rather, we are dealing with many understandings of this term and thus many variations of different groups in regions of the Indian Peninsula. The topic has an enormous literature and is a classical topic in the anthropology of India (see Bougle 1971; Dirks 2002; Dumont 1974; Ghurye 1961). Given that complexity, I am focusing on selected examples. A certain outline of a society based on castes began to crystallize in the second century B.C., with the onset of the colonization of the Indian sub-continent by the Aryans, who had migrated there from the northwest. The Aryans began to 
take control over the territories of what is today India and Pakistan, incorporating subsequent tribes into their community (Kieniewicz 2003, p. 37). This incorporation went hand in hand with a painful status degradation: members of the tribes existed on the margins of the society.

Even though caste was surely being transformed as a performative and changeable entity before the arrivals of the Europeans (Reddy 2005, p. 548), the time of colonial India seems to have meaningfully influenced what we understand under the term "caste" today. As Nicholas Dirks argues, caste is not "the unchanged survival of ancient India, not some single system that reflects a core civilizational value, not a basic expression of Indian tradition", but rather "a modern phenomenon, that it is, specifically, the product of an historical encounter between India and Western colonial rule" (2002, p. 5). Dirks deems caste before the British to be one of many Indian identities, where, after the British, caste "became a single term capable of expressing, organizing, and above all «systematizing» India's diverse forms of social identity, community, and organization (ibidem, s. 5)". I believe it is not British rule which changed inbuilt Indian social entities, Indian identities, and what lies beneath them. The complexity of caste and other identities was and still is there, but due to colonial writing and discourse, the outside world started to perceive Indian society in a simplified way based on the concept of caste. This is also supported by Indian thought. The disagreement of Indian researchers is an important voice of agency in the subject of their own history. In the book Debrahmanising History Mani Braj Ranjan says that even if colonialism, as stated by Dirks, had influenced the meaning of caste by giving it a superior importance, caste was not only one of many Indian identities. It was still the basis of social identity. According to Mani "caste had percolated every core of social and political life in India when the British established their rule (2005, p. 198)". On the basis of my own research I would argue that caste with its clear rules of application in practice has many layers and dimensions, and that different identities as that of regional or local communities, kinship groups, temple communities, political affiliations and others are also still very much visible in Indian society.

Users of the Konkani language in Kochi declare their feeling of belonging to one of the five aforementioned castes. The term varna, in turn, which is closely linked to the caste system, was occasionally used by my interviewees in speech interchangeably with caste, although it means a different notion altogether. Varna refers to an ancient hierarchical division in the Indian social system where there are Brahmins (priests), Kshatriyas (warriors), Vaishyas (merchants) and Shudras (service providers). Nowadays when members of the caste group define themselves as a part of a particular caste, it also indicates their place in the hierarchical idealized order of varna. Thus, Goud Saraswat Brahmins and Sonar (Daivadnya Brahmins) would call themselves Brahmins, although not everybody would consider them as such. It depends on who is speaking. Goud Saraswat Brahmins would not consider Sonar as valuable Brahmins, because the latter eat fish. The local Keralan Namboodri Brahmins would not recognize either the Goud Sarawat or the Sonar as Brahmins since they travelled 
through the sea, which is considered polluting. Vaishya Vani recognize themselves as Vaishyas; Kudumbi as Shudras (although they would not be particularly proud of it); and Sarasvat in turn would consider themselves again as Brahmins in disguise, who due to social abuse were put in the place of the Shudras since their ancestors were the illegitimate children of girls from Goud Saraswat Brahmins who have been dancing in the temples (devadasi dancers) since they did not marry "on time". The Goud Saraswat Brahmins men have been there so-called patrons. This gave these patrons sexual privileges over dancers. In short, the example of the Konkani caste shows how difficult it is to qualify any group members to a fixed category of varna, because it truly depends on who is speaking.

One significant difference in regard to the caste is the fact that varnas, in the eyes of my respondents and generally, as part of common knowledge in India, apply to the entire sub-continent and are primarily linked to ritual status and to concepts of dharma and karma. Artur Karp, a researcher of India and one of the best experts in this topic, lists the most significant distinctive features of a caste in a transparent manner. The term caste originates from Latin and in some parts of India is often interchangeably used with its more Indian version, jati- sanskrit for "birth" or "tribe", although the Konkani themselves do not refer to themselves with the term jati, since it is of north Indian origin and they rather use the term caste - more common in Kochi. Jati or caste is a closed group characteristic for India, and one can only belong to it by birth. It is closely linked to profession, which is also passed from one generation to another. Because of the foregoing, one's social role has been traditionally determined by birth. Moreover, castes have been defined by the customary division of work in a given region, and so the specific composition of society in terms of caste groups has depended on the exchange of services in the local dimension. In the context of the Kochi Konkani this is a very significant observation. The division into castes, which to this day exists within this group, is most likely connected to the distribution of castes in Goa, from where the Kochi Konkani came.

Another frequently stressed distinctive feature of caste is the way in which it separates itself from others and thus creates the group's boundaries. In its traditional form, a caste is an endogamous group, which means that marriages are contracted only within this group. If it happens otherwise, as for example in the case of the Nair in Kerala, a specific group of matriarchal warriors, then the rules of forming intergroup relationships are strictly defined and they fit into the frameworks of culturally recognized hierarchical principles. This characteristic - hierarchy, is no less important in the classic approach to a caste, as belonging to a given caste group indicated one's place within the social hierarchy. It is also associated with the concepts of symbolic purity and impurity. They apply, for example, to the food eaten and from whom one receives it, or the type of work one does. The best example of a "pure" profession was the expert of old texts and books and teaching them, while the most "impure" one is that of an undertaker. The mutual separation of castes was also a result of differences such as dialect or language, rituals, oral traditions, other customs, dress or separation of self-governance in the form of the so-called panchayats (Karp 2002, p. 387-388). 
Pauline Kolenda's definition ${ }^{9}$ of caste puts emphasis on the fact that it is an origin group for a special role - a group that integrates through the traditional, local, or regional system of interdependencies and exchanges with other groups. A caste may, but does not have to have a characteristic subculture (Kolenda 1958, p. 9).

Already in the $19^{\text {th }}$ century there were reformist voices calling for the abolition of the caste system and its attendant social exclusion. Such postulates were put forward, among others, by the reformist grouping Brahmo Samaj. By the early $20^{\text {th }}$ century, the disillusionment of Indian society, raised in a democratic spirit, with British colonization, spurred an increasing number of activists to take up a fight for the rights of the economically disadvantaged, of those deprived of ritual rights, such as access to temples, and of political rights. The liberation movement of Mahatma Gandhi was of course a part of this new trend (cf. Kieniewicz 2003).

In 1947 India gained independence. The newly adopted constitution officially abolished the caste system. All citizens were legally guaranteed access to such basics as water, land, public spaces, temples, schools, and courts of law ${ }^{10}$. So-called "backward castes", the unprivileged communities, representing ca. $25 \%$ of the population ${ }^{11}$, were given a guaranteed quota of spots in universities and in state offices. Independence and the new egalitarian legislation mark a breakthrough moment from which significant transformations of Indian society began. Seven decades later, castes still exist in Indian society, but they have undergone considerable changes. One of the interviewees describes it this way:

After getting independence the people who shaped the constitution, they found out that a section of people is marginalised, ok? These Brahmins have acquired lot of things and they have marginalised other sections, ok? [...] what happened was that this fourth one shudra, they got marginalised they are working class. [...] We have such a dark history (Goud Saraswat Brahmin, 27.12.2015, Kochi, male, 40).

This opinion shows the thoughts and doubts people themselves have, and also indicate that caste members see the past from various perspectives, not only their particular one. The caste system has been the subject of many descriptions and interpretations in the field of social sciences. The most seminal work and the point of departure for social research on the caste system is that of the sociological approaches presented by Louis Dumont in his 1966 Homo Hierarchicus. The sociologist defined the castes as a hierarchical system based on concepts of purity and impurity. According to Dumont, secular power was subordinate to ritual status within this framework system. This is one of the most frequently discussed aspects of his approach. Simplifying, could it really be true that ritual authorities were above the money system and its

9 Well-known American anthropologist conducting long-term fieldwork in India.

${ }^{10}$ Source: Portal of India, Constitution of India

https://www.india.gov.in/my-government/constitution-india/constitution-india-full-text, access 11.07.2020.

${ }^{11}$ Source: Office of the Registrar General \& Census Commissioner, India http://censusindia.gov. in/Census_Data_2001/India_at_glance/scst.aspx, access 12.03.2019. 
importance? From the 1960s to 80 s the question regarding the dominance of ritual status over political or economic power remained one of the most intensely discussed topics in the anthropology of South Asia. Were territorial or economic issues really peripheral? Such an unambiguous distribution was idealistic, and the reality could have diverged from it significantly in the past. Currently, these meaningful elements certainly overlap. There are contexts in which ritual purity is still a priority, but economic power often has great significance as well.

[...] as I said there is something more than the caste system which keeps you together. It's the language and all the things which are brought together from this different state. And that makes you like, kind of community more closer to each other than for example with Malayali. [...] Like Konkani (Vaishya Vani, 10.11.2014, Kochi, male, 35).

Custom wise, if you think of custom wise, there is no uniform custom between communities, each [Konkani] community has its own practices (Goud Saraswat Brahmin, 03.12.2014, Kochi, male, 60).

Other classical caste theories (Bougle 1971; Ghurye 1961) also stress the importance of hierarchy in the caste system, in relation to the numerous restrictions connected with food - namely, who can receive food from whom and who cannot. The simplest example illustrating this phenomenon is the fact that Brahmin priests make food that is pure for all castes, while those on the lowest rungs of the social ladder, the so-called untouchables, "contaminate" the representatives of other castes with their food. There are also other meaningful aspects, such as having or not having certain privileges. Areas of symbolic purity and impurity, and the profession acquired by birth, are very important. This is also connected with restrictions concerning the choice of marriage partners. There are not only clear rules regarding permissible marriage partners. Moreover, some aspects that are not precisely set turn out to be significant.

Hinduism is a federal system of castes. Federation of castes. The cultural ties are so strong in Hinduism, when it comes to marriage, we don't allow our children to marry from other caste. We will say sorry, why should we proceed like this, why should we create problem for our children, we can choose from our own caste. That's the problem. Caste is so prominent like religion. Even if he was a friend, he will come to our house attend all programs, hangout with us, even live in our home, but marriage I will not take. There are love marriages nowadays, there are so many love marriages but arranged marriages will be the fuel (Sonar, 18.11.2014, Kochi, male, 45).

Same ceremonies we continue, same ceremonies. Slight changes will be there and there is more the language influence. Malayalam is the language of the state, so we are formally [Keralan], even now majority of people are doing business here [in Mattancherry], even now we talk in Konkani. Only in school we talk in Malayalam (Goud Saraswat Brahmin, 15.11.2015, Kochi, male, 70).

In analyzing the issue of Konkani castes, I will refer for comparative purposes to the existing case studies concerning other regions of the country (i.a., Demski 2007; Gomes 1987; Mines 1984), as well as to the classic thought of Louis Dumont who defines the caste as a hierarchical system based on signs of purity and impurity (Dumont 1974) and the later critiques of his work. Above all, it is not recommended 
to deem the reality of caste as representative for all of India, as social systems in this enormous country are much more complex, and the "idealistic, hierarchical division connected to religion cannot be applied to the same extent to every region" (Natrajan 2005 , p. 227). In contemporary Indian debates, the caste is believed to be a historical construct, simplified, linked to colonialism and superficial scholarly works written primarily so that the colonizing powers could get to know the conquered country. The British attempts at classifying social systems were in turn based mainly on examples from northern rural areas, and they omitted the urban context (Reddy 2005, p. 547). Louis Dumont (1974) assumed that secular power was subordinate to ritual power, and later researchers have not agreed with his point of view (Appadurai 1992; Dirks 2002; Gupta 2000; Natrajan 2005). Moreover, limiting the issues of caste to religious content is not correct, as religious groups are not different from each other merely in the categories of denomination, and due to this - a matter of particular significance for my considerations - they can be analyzed as ethnic groups (cf., Kurien 2002; Brass 1991; Phadnis 1990; Schermerhorn 1978).

The working definition of caste that I will use in this work is based on the proposal of Balmurli Natrajan. He views the caste as both a social group and a social practice subject to rapid changes in contemporary India. Traditionally, caste has been based on systems of dependencies, hierarchy, and separation, although in each region they could differ, adapting to local systems and possible mobilities. In today's India, the latter element, that is separation, is still heavily practiced, representing the last bastion of traditional power relations, while the former two, dependency and hierarchy, are in a state of collapse (Natrajan 2012b, p. 16-17). Adrian Mayer observes that purity of caste has lost importance in favour of difference (Mayer 1996, p. 60), understood as cultural difference. Within this approach, the caste becomes more of a cultural identity, which is often used as a disguise for maintaining traditional norms in a time of multiculturalism and alleged equality (Natrajan 2012b, p. 160).

\section{ETHNICITY IN THE INDIAN CONTEXT}

In answering the question about strategies of separateness in the dual caste and ethnic system in place in Kochi, I relate to theories from the anthropology of ethnicity by Indian researchers (Natrajan, Reddy). In this vein, I perceive the Konkani practices of maintaining group separateness as a dual identity system, in which both caste and ethnicity matter. Ethnicity is understood here as boundaries within which the group members operate and define themselves as part of a particular community, and only those features (which are given importance by the people involved, the group members themselves) matter. Application of theories from the anthropology of ethnicity supports the recent analysis of what happened with the caste system and how it is changing as a result of its existence in a multi-lingual, multicultural, multi-religious environment, one composed of populations originating from various regions of the country, in which lingering traces of colonialism are still visible (as exemplified, 
for instance, by Anglo-Indians). The caste as a performative and changing phenomenon (Reddy 2005, p. 548) is subject to transformations which stem from modernity and global mobility. One of the important questions for me was how these phenomena affect the ethnic self-awareness of caste (Barnett 1975). This does not mean mobility did not exist before, but what can be researched now are contemporary practices and tendencies.

Within this understanding, caste as social group and social practice moves toward ethnicization, visible in the actions of Konkani castes, and may be perceived as a strategy of renaming and preservation of the old order in a new reality, in which legacy is much more respected and valued than the caste system, for which there is no longer room in the new political arena. Importantly, the new Konkani movements aiming to reunite the group in Kochi and in India (as well as members of the community who have settled abroad) may be a method of keeping the traditional order and of maintaining power in the hands of those who held it before. I mean here primarily the Goud Saraswat Brahmins.

When Brahmins came [around $9^{\text {th }}$ century AD], they brought the four-systems like the four different level caste like Brahmin, Kshatriya, like that. Before that, that system wasn't here in Kerala (Vaishya Vani, 10.11.2014, Kochi, male, 35).

One outcome of this phenomenon is that conflicts and misunderstandings arise among representatives of Konkani castes. This makes the topic all the more interesting, as various interests or agendas clash in the process of creating the imagined ethno-political community.

Focusing on the contemporary transformations of castes toward ethnicization (Barnett 1975, p. 158-159), and the meaningful signs of ethnicity, such as religion, regionalism, language or the caste itself (Reddy 2005, p. 548), has allowed me to explore how the boundaries between different groups living in Kochi and between Konkani castes are created. What makes it possible to define an ethnic group is not so much the culturally determined group of people with particular features located within its boundaries, but above all the ethnic boundary which is there even if people within the group show signs of mobility (Barth 1969, p.9-10).

While exploring the strategies of maintaining group identity in the dual casteethnic system that I have encountered in Kochi, I address the theories of Indian researchers (Natrajan, Reddy) worked out by the anthropology of ethnicity. These theories have helped me identify the problem of creating group boundaries among the Konkani, but also among other communities inhabiting Kochi. I perceive the ethnic theories of Natrajan and Reddy as a useful point of departure for interpreting and understanding the contemporary practices of maintaining (or creating) group separateness and integration. In my opinion the caste is a value that is subject to transformations (Reddy 2005, p. 548) which, as everything else in culture, changes under the impact of social and political shifts and the immense influx of external influences brought on by global mobility. This creates a new context to caste mobility, where officially there is no caste system, but paradoxically it is taking place in an independent, 
democratic country, open to the global world. Nowadays caste mobility differs from that in the past ${ }^{12}$. The key importance to me was understanding how the meaningful elements affect the newly formed ethnic awareness in castes, or, as Stephen Barnett puts it, the contemporary transformations of the caste toward ethnicization (Barnett 1975, p. 158-159). As a consequence, "ethnic symbols" of importance to the people researched, or signs such as religion, regionalism, language, caste, or even regional cuisine (Reddy 2005, p. 549) are phenomena that manifest themselves in everyday lives and show the construction of group boundaries between various communities inhabiting Kochi, including the Konkani.

What is generally understood as "casteism"13 may be perceived as a monopolistic practice of a particular caste which avails itself of strategies of separation, domination, exploitation, and stigmatization, based on the identification of a person or group of persons with a given caste community in Indian society (Natrajan 2012b, p. xvi). The diversity of caste systems supports monopolistic caste practices, whereas members of a group are "frozen" in the same place within the socio-economic system. The segregation and separateness of caste, which do not render themselves to change easily, are ensured because the labour, capital, and marriage markets are divided into caste segments (ibidem, p. xvi). The term 'monopolistic' refers to Brahmin or other castes occupying the highest positions.

Ethnicization of a caste, well grasped by Chris Fuller, is a process within which a vertical hierarchical system, internally integrated, falls apart into a separate, nonintegrated and horizontal (by definition: egalitarian) ethnicity (Fuller 1996, p. 26). In the case of the Konkani, this process is taking place right now. On the one hand, we are observing a strong caste identity, in which belonging to one of the five castes and the accompanying attachment to customs or behaviours are important elements of identification and self-image. Attachment to the caste-based community tends to be deep. The celebration of holidays as well as the daily life in general of a Brahmin looks very different from those of a member of the Kudumbi community.

I2: Kudumbis they speak Konkani, not like us.

I1: Their accent is different madam.

I2: Not much difference, but the difference is that actually they do not speak that much Konkani with us. They speak Konkani within them and we do not allow that much Malayalam to enter in our community. The Malayalam knowingly or unknowingly goes inside their community, that is what makes the main difference. The main thing is that they only speak Konkani within themselves and not with us (Goud Saraswat Brahmin, 04.01.2016, Kochi, I1 male, 40, I2 male 12).

On the other hand, among the Konkani castes there is a nascent awareness based on language and purported origins, which in its declarative form is to have the nature of an ethnic community.

${ }^{12}$ Castes could have shifted their position in the traditional system basing on adopting particular ritual rules, which have been putting them higher in the caste hierarchy.

${ }^{13}$ Casteism is a contemporary tendency to maintaining caste identity. 
Similarities could be there yes, because they lived as neighbours back in Goa, these communities were neighbours (Goud Saraswat Brahmin, 03.12.2014, Kochi, male, 60).

If there was no this Kudumbi community, then Goud Saraswat Brahmins would not have come to Kerala. That is a real fact. [...] What I mean like this [Kudumbi] community agriculture is fisherman and sea going people, if history is correct, somewhat it is correct during the Portuguese inquisition and conversion period 20,000 families including Goud Saraswat and Kudumbis came to Kerala, through sea route. This Goud Saraswat Brahmins have been taken by in the boat, rural boats they had to be taken by this Kudumbi people. So he [friend of the speaker - A.K.-S.] has admitted that historical fact, even though he is a Goud Saraswat Brahmin but some old conservative people [would say - A.K.-S.]: how can the Kudumbi people take the GSB? GSB has taken Kudumbis, some say. But the fact is, he has admitted clearly that. That is also given. You will get a good idea, ok? (Kudumbi, 11.01.2016, Kochi, male, 65)

The Konkani group is a good example of another interesting phenomenon: a situation in which old norms regarding the caste system still persist and are enforced by the members of communities, especially the more privileged ones, such as the Brahmins, though at the same time they co-exist with the concept of egalitarian ethnicity.

They came here to do household work, for Brahmins that is why I told, you know, that is the dark part of our culture, that nobody will tell you or they may have forgotten. For example, my home works are done by them. We cannot do works that perfectly and you know I can wash one or two clothes at a time, but these people know... they can wash 20 30, they do not have any problem. We have, we are not as healthy as them that is one. [...], one thing is that there was a time when we Brahmins joined other groups, I cannot isolate ourselves from that, from that responsibility, we are also responsible for that. There was a time, dark time, the period when we considered other sections as outcast. So, what I am going to tell you is the dark (Goud Saraswat Brahmin, 04.01.2016, Kochi, male, 40).

Therefore, I cannot say one identity is more important than the other, because both caste and ethnic egalitarian identities are functioning simultaneously on different levels of daily life. As a result, both are intertwined in the Konkani environment and have strong political colouring. In the case of Goud Saraswat Brahmins, even the clothes and the way women wear flowers in their hair will be a clear sign for those familiar with these nuances to which group they belong. Political views can also signal membership. The Konkani Brahmins support the pro-Indian BJP party, the Kudumbi - the communist party, and Christians living a few streets away - Congress. Groups create a border between them that gives them self-knowledge about their belonging. At the same time, ethnic boundaries are relational and change with changes in the thinking of individuals within ethnic groups, because they are symbolic, and it is individuals that create them.

The question is whether in this context I can call the Konkani language users the "Konkani group" or the "Konkanis". I have chosen this form because firstly my interlocutors use this term, and secondly people who refer to themselves using this term form a group that consciously sets itself apart from the rest of the Kochi multi-group environment. Nevertheless, within the Konkani group, there are sub-groups that derive their genesis from an entirely different identity concept - the caste concept. Both answers seem valid according to the interlocutors. 
These changes in the process of creating their own identity are also propelled by political issues. Multiculturalism ${ }^{14}$ as opposed to a multi-caste system is the image of Indian society endorsed by the country's government (Natrajan 2012b, p. 4). This applies not only to the reason why the Konkani group acts to build a cohesive ethnic community. It also applies to the very unit of caste. Multiculturalism and stressing cultural distinctiveness have been a strategy for securing the public existence of caste within society, but not openly. The caste that presents itself through the category of heritage fits within the frameworks of the country's cultural legacy, and it needs not fear invalidation as the last bastion of the old, hierarchical, and segregationist tradition, seen as something negative in democratic India. Culture and ethnicity are signs of the wealth of diverse Indian civilization (ibidem, p. 4). The phenomenon of protection of heritage fits into the global leaning toward political correctness, in which giving legitimacy to "cultures" has a great significance. In this way, Konkani castes as well as Konkanis as an ethnic entity can seek political recognition as cultural identification and demand respect and protection for themselves as contributing to cultural diversity (ibidem, p. 4).

My fieldwork proved that ethnicity comes to aid here; in such a meaning, a caste and group of castes as a cultural community can be a convenient framework for the group's survival. It is a modern strategy of coping with limitations of state policy, which officially abolished castes. Even though in India other variations of creating community above the caste might have existed ${ }^{15}$, I see the ethnicity example of the Konkani people as a new phenomenon which is set in a totally different, modern context. It should also be noted that ethnicity still functions broadly within the context of tribes in modern Indian texts, and the term "ethnic" or "tribal" are connected. They are used to describe separate groups with characteristic cultural heritage, inhabiting a concrete territory in geographical isolation and often lacking education (Kolas 2015; Priya 2016). Currently, as in the case of the Konkani, the term "ethnicity" is chosen by the group members as well-fitted to the character of their group, and it has nothing to do with connotations with tribal cultures, which are colloquially associated with social backwardness. The meaning that contemporary groups adopt is closer to the foreign definitions of primordial ethnic groups, whereas it is possible to use a new formation and interpretation of one's own culture, usually based on language and place of origin, without compromising status.

Dagnosław Demski writes in one of his works about traditional caste formations in Gujarat in 1990s:

The caste system has now collapsed in India. What does this mean? A network of hundreds of groups and subgroups circling around local centers and living in smaller or wider clusters have loosened or definitely lost their traditional strictness. Most of the groups and subgroups have been

14 This notion was brought to this Indian debate by Balmurli Natrajan.

${ }^{15}$ For example kind of grouping called 'Ter Tansli' in Gujarat, a kind of solidarity organized around local economy exchange around the Rajput court, a kind of clientele consisting of the princedom and its servants (Demski 2007, p. 32). 
preserved as collective entities, but the former connections and dependencies have emerged [have led to the emergence of - A.K.-S.] a new landscape of groups openly competing between themselves for resources, often on the markets previously forbidden to them. Such a change has influenced the economical and cultural area of their welfare and collective life, including myths, symbols, rituals, etc. (Demski 2006, p. 214).

The structure of group survival in the world of today chosen by the Konkani understood as an ethnic formation, has become a new strategy of existence in contemporary India.

As an ethnic group, castes are not deprecated due to their genesis and history, which are in opposition to the democratic idea of statehood. On the contrary, in this form, castes can be visible in the public arena as political actors to be reckoned with. They can also enjoy privileges granted to them by the legislation with the aim of preserving the purported shared culture in the famous Indian cultural mosaic.

The law, the central government [is - A.K.-S.] making all the people eligible for the property (Goud Saraswat Brahmin, 07.11.2014, Kochi, male, 70).

Government has some grants, government will give some grant. If you publish a paper in Konkani because it is a scheduled language, so every other language Malayalam, Sanskrit or Hindi, all these languages there is some grant given by the government. People are doing $\mathrm{PhD}$ or MA, they are giving a thesis or paper presentation or something like that (Goud Saraswat Brahmin, 17.01.2016, Kochi, male, 35).

Ethnicity and privileges granted in its name are also a significant political factor in the struggle for votes (Natrajan 2012b, p. 5). Due to all of the above factors, it could be said in the language of economics that it simply pays to be part of a cultural collectivity that an ethnic group can be, while it does not pay to be a member of a caste, which has suffered degradation in the political arena. Dipankar Gupta put it this way: "No matter which way one looks at the caste, the system, such as it was supposed to have been, has clearly collapsed" (Gupta 2004, p.x)". Officially abolished, the caste might not exist as a system, but it clearly does exist as a cultural community.

The example of the Konkani in Kochi shows that while developing and negotiating among themselves an ethnic community based on origin and language in an environment familiar over generations, they still feel well within their caste groups. They are subject to changes, but they still exist in their contemporary form. As a collectivity of individuals eligible to vote, the caste is also becoming a less obvious target of political measures aimed to secure votes. Caste separation ensured by endogamous marriages is still of great importance to caste members (Natrajan 2012b, p. 11), which was also confirmed in the field and any exception, like love marriages, is a big issue, which everyone either gossips about or is not particularly happy about.

Yeah, unfortunately my wife comes from a different caste, she's not a Vaishya. [...] She's known as a... kind of, mother is Christian, father comes from other, it's called Irava. They are... like uh, original tribes. Here in Kerala there were lot of people (Vaishya Vani, 10.11.2014, Kochi, male, 35).

It's usually arranged marriage. Only some cases men when there is a love marry is ... happens. Like very rare. Like love the Christians, Muslims - these are very rare. [...] It want to stick to traditions, to culture. [...] And anything outside of their culture would be viewed with danger. So they don't want 
to lose that... [...] you go for arrangement, they're looking into communities. Inside communities. They don't look outside the communities. That's tradition, that's... Because, when you marry inside the community, there are conveniences. Because of lot of understanding. With the traditions, cultures, with a language. [...] You know you can understand the culture and the traditions. So that's less strain, let's stress on the couple. I think that's why... [Goud Saraswat Brahmins and Vaishya Vania] They would be sharing a lot of traditions and cultures. More than the Malayali. So it's easier, it could be easier for a couple, when you're talking about marriages, it would be easier for the marriages with GSB and Vaishya than a marriage between GSB and Malayali. It would be easier between the GSB and the Vaishya because they're sharing a lot of traditions and cultures and language. Food for example. But in this particular case where a lady a gsb lady, leaves her home and goes behind some outcast we treat them as outcast and we do not allow her to enter at that time. [...] Mental division or a mental distance is kept. Ok? We have seen her suppose in some temple, she will not come. She has become a part of them like there. (Goud Saraswat Brahmin, 04.01.2016, Kochi, male, 35).

Now our people marry [outside community] because there are a little shortage of girls, because everybody wants maximum one child not the second one. They are going on family planning. Whereas if you see the population of the Christians and Muslims, it is higher, maximum Muslims are increasing (Goud Saraswat Brahmin, 15.01.2015, Kochi, male, 70).

We are following the Hindu community and Hindu culture we are following. Specially means everybody those who are following the Hindu culture even though there are some regional differences so that is what in our community also it is there. In marriages and performing the pooja and like this temple, there is small small differences in communities (Vaishya Vani, 10.11.2014, Kochi, male, 45).

This loyalty to the caste system's rules and restrictions combined make the formation of caste equally important as the formation of ethnicity, but both function in somewhat different spaces and contexts in the lives of members of groups such as the the Konkani.

Castes cannot be clearly articulated in the political arena. The contemporary law forbids this by criminalizing untouchability, that is social exclusion based on caste segregation and being outside of the caste system, and it prohibits discrimination based on caste origin at work and in all other spaces of public and private life. Casterelated crimes are severely punished (ibidem, p. 11). Despite these stern sanctions, casteism, or discrimination based on caste, is still present under the surface of labour practices, educational institutions, and certainly in matrimonial and other spaces of life. The breaching of caste boundaries elicits various kinds of violence (ibidem, p. 11). Among the Konkani, this is manifested in the way the Brahmins distinguish and treat people from outside their caste. Representatives of other castes are not allowed into temples, they have access only to strictly determined spaces, and during holiday celebrations that may participate in only certain rituals.

Distinction and discrimination occur within the Konkani castes, but also at the points of contact with other groups living in Kochi. One good example is a friend of mine who is a member of the merchant caste - Vaishya Vani. He is an administrative employee at a university and has held this position for years. Konkani, as a group originating from the north, use surnames, unlike people from the south - the local Dravidians. My friend, not wanting to reveal that he is a descendant of migrants from the north, never used his surname at work, instead writing his name in the southern 
manner (where the function of surname is taken by the first letter of one's father's name). As he explained to me, he feared that if he had revealed his true identity, he would not have been hired, or would be treated worse at work ${ }^{16}$. This shows how difficult it is to define the caste system in a generalizing manner. Vaishya Vani are potentially a group having a relatively high status in the caste hierarchy. They are also well-educated and quite well-off. Nevertheless, in relations with local groups, what degrades the status of this community is the fact that they arrived from elsewhere. What matters here is that the Kochi community remembers - it does not matter that the Konkani have been in the region for five hundred years. They are still a separate, foreign unit, which seems to be upheld by both the representatives of local Keralites and the Konkani in the way they isolate themselves. Applying Dumont's thought to the concept of the caste system on this small scale, it may be summed up that the caste system is a system of relations, of the ways in which the individual components interact, and not a system of separate elements (Dumont 1974, p. 40).

\section{CONCLUSION: FROM CASTE TO MULTI-LAYERED IDENTITY}

A paradoxical situation can be observed in contemporary India: castes exist without the caste system, while caste-based discrimination (casteism) functions without its traditional legitimization (Natrajan 2012b, p. 11). Max Muller wrote as early as 1869 that castes cannot be abolished in India and that attempts to do so would be socially dangerous. He believed that the caste system would die out as a religious institution, but that it would survive and grow in strength as a social one (Muller 1869, p. 353). The observations of later researchers have confirmed this. The caste system has lost its meaning as groups based on ritual status, but it has prevailed as a community, and its members seek ways to achieve their political goals with other similar communities (Sheth 1999), for example based on ethnic factors like common cultural heritage, sense of origin, and language. One of the fundamental features of the caste system is aversion or difference (Mayer 1996, p. 62; Natrajan 2012b, p. 16). It functions as a system of kinship, a source of contacts with "one's own", a pressure group, an organization, or an ethnic group (Kolenda 1978, p. 9). A "vertical social system" defined through hierarchical relations is in collapse and castes are becoming more "horizontally" separate, changing into ethnic groups, probably diverse ones owing to their different lifestyles (Fuller 1996, p. 22). The awareness of caste difference is very deeply rooted, but the traditionality of caste has undergone changes and new ethnic identities appear:

I don't practice the rituals and the other what is that, whatever is prescribed for Brahmins. I am not a practicing Brahmin or a Hindu, but I was born a Brahmin. I am not doing any of the work which a Brahmin should do. I was a banker by profession and by another career I am a writer. In a caste view

${ }^{16}$ This piece of information, like many others, was given to me in the course of many meetings and discussions that were not recorded, and which were in effect "participant observation". 
you are established on the basis of one's work. That was the basis for this caste. Over the caste of udba, and their profession is making pots. There is a caste of iravas, their profession is climbing the coconut tree and making poddy. Okay? so every caste has got a profession attached to it from immemorial times. Now that has been delinked. In India, modern day caste the people belonging to any caste are mostly not practicing the profession or the occasion associated with that caste, nowadays, okay? If you ask anybody, I belong to Brahmin community but he doesn't know Veda, he cannot even recite the first sentence of the Veda. He cannot mention how many Upanishads are there. But he claim to be a Brahmin. Practically what has happened is the profession has been segregated from the caste to which it was associated from time immemorial. [...] so, we [Konkani] will be where we are, in the foreseen future. Unless some miracle happens [...], we will be where we are. Continuing to live in the various parts of the country. But we want to strengthen our channels of communication. We need to introduce new channels where channels are not existing to bring these dialects together and to allow them to function together before standardization falls and to bring down the number of scripts used for writing Konkani (Goud Saraswat Brahmin, 23.01.2016, Panaji, male, 60).

Moreover, the so-called samaj ${ }^{17}$, that is, local organizations of different Konkani castes that function as interest groups within civil society, are present and growing. They are publishing magazines, books and booklets, organizing seminars and interests circles on Konkani-related topics, by which they influence ethnic awareness within the Konkani-speaking communities. The shift that is taking place in the Konkani's understanding of their own group is very significant here. Under the influence of measures pursued by activists to promote their language, new identifications are emerging. On the one hand, caste affiliations still function in the local dimension, where all the members of the community know each other through daily, direct contacts. This is now accompanied by a consciously created, much broader ethnic affinity, which entails the Konkani people of different castes, including those who reside in different regions of the country. As a result, various identities coexist at the same time. It is to paraphrase Anderson (2006) an 'imagined ethnic community', imbued with a sense of unity by contemporary institutional actions.

Actually now the Konkani culture is getting support from more associations now. [...] Different organizations conduct different seminars. This particular event [Konkani Perishad] they are conducting every 2 years. [...] It will be in different regions like 2 years ago it was in Karnataka. [...]. There are also Konkanis (Goud Saraswat Brahmin, 04.01.2016, Kochi, female, 40).

At the same time, however, the caste continues to exist in a transformed model. Nevertheless, the traditional caste purity has lost importance in favour of cultural differences. This otherness still constitutes a basis for the Konkanis' separation in Kochi, because of their different cultural background. Cultural separateness, recognized as important by caste members, is becoming a strategy for the survival of the caste community in contemporary, democratic India. The caste as a social practice is subject to transformations brought on by modern social, political, and global processes. Yet what allows the caste to survive in the everyday sphere is precisely the emphasis on differences that encompass various aspects belonging to the groups' heritage,

${ }_{17}$ This is just a term signifying association or assembly, and is not related to Brahmo Samaj - the religious reformist movement in Hindu religion, influential to the making the modern India. 
languages, customs regarding such areas as cuisine, celebrations, rituals, and choice of marriage partners. Ethnicity creation thereby ensues, giving space for cultivating what is considered traditional and essential for the survival of communities in the modern times. It helps the Konkani avoid merging with other communities of Kochi or wider - India. A shared heritage reminds members of the Konkani group of who they are, what their cultural background is, it retells their place and sense of their origin, fulfilling a tremendously important function of consolidating distinctiveness amidst multicultural neighbours and external influences. New identities emerge, however, whether ethnic, national, connected to education, profession, or determined by the level of wealth. All this means that in a contemporary Indian city such as Kochi we can observe the coexistence of many different identities.

\section{LITERATURE}

A n d e r s o n B e n e d i ct 2006, Imagined Communities: Reflections on the Origin and Spread of Nationalism, Verso, London.

A p padurai Arjun 1992, Putting Hierarchy in Its Place, [in:] George Marcus (ed.), Rereading Cultural Anthropology, Duke University Press Books, Durham, pp. 34-47.

A p padurai A r j u 2005, Nowoczesność bez granic: Kulturowe wymiary globalizacji, translation Z. Pucek, Universitas, Kraków.

A p padurai A r j u a 2009, Strach przed mniejszościami. Esej o geografii gniewu, Wydawnictwo Naukowe PWN, Warsaw.

B a r n e t t S t e ve 1975, Approaches to Changes in Caste Ideology in South India, [in:], Burton Stein (ed.), Essays on South Asia, University Press of Hawaii, Hawaii, pp. 149-180.

B a r th Fred rik 1969, Introduction, [in:] Fredrik Barth (ed.), Ethnic Groups and Boundaries: The Social Organization of Culture Difference, Johansen \& Nielsen Boktrykkeri, Oslo, pp. 9-38.

B e r $\mathrm{n}$ a r d K. L. 2015, History of Fort Cochin, n.d., Fort Cochin.

B o u glé Céle st in 1971, Essays on the Caste System, University Press, Cambridge.

B r a s s P a 1 1991, Ethnicity and Nationalism: Theory and Comparison, SAGE Publications, New Delhi.

D e m ski D a n osław 2006, Questions of Inequality and Collective Experience. Hinduism from Several Different Perspectives, Archeologia Polona, Vol. 44, pp. 213-230.

D e m ski Dagnosław 2007, Obrazy hinduizmu. Kultura i religia oczami radżputów i pasterzy, Instytut Archeologii i Etnologii PAN, Warsaw.

D ir k s N i ch ol a s 1996, Introduction, [in:] Cohn Bernard, Colonialism and Its Forms of Knowledge: The British in India, Princeton University Press, Princeton, pp. ix-xvii.

D irks Nicholas 2002, Castes of Mind: Colonialism and the Making of Modern India, Princeton University Press, Princeton.

D u m o n t L o u is 1974, Homo Hierarchicus: The Caste System and Its Implications, University of Chicago Press, Chicago.

Fulle r Ch r is 1996, Introduction: Caste Today, [in:] Fuller Chris (ed.), Caste Today, Oxford University Press, Delhi, pp. 1-31.

Ge e rt z Clifford 1973, Interpretation of Cultures. Selected Essays, Basic Books, New York.

Ghurye Govind S a d s hiv 1961, Caste, Class, and Occupation, Popular Book Depot, Mumbai.

Gu p ta D i p a k a r 2000, Interrogating Caste: Understanding Hierarchy and Difference in Indian Society, Penguin Books, New Delhi.

Gupt a D i p a k a r 2004, Introduction: The Certitudes of Caste: When Identity Trumps Hierarchy, [in:] G. Dipankar (ed.), Caste in question: Identity or hierarchy?, SAGE Publications, London, pp. ix-xxi. 
Ka r p A rtu r 2002A, Kasty hinduiskie, Religia. Encyklopedia PWN, Vol. 5, Wydawnictwo Naukowe PWN SA, Warsaw, pp. 387-388.

Karp Artur 2002B Manusmriti, Religia. Encyklopedia PWN, Vol. 6, Wydawnictwo Naukowe PWN SA, Warsaw, pp. 405-407.

K i e n i e w i c z J a n 2003, Historia Indii, Zakł. Nar. im. Ossolińskich, Wrocław.

Kolås Åshild 2015, Framing the Tribal: Ethnic Violence in Northeast India, Asian Ethnicity, Vol. 18, pp. 22-37.

Kole nda P a u line 1985, Caste in Contemporary India: Beyond Organic Solidarity, Waveland Pr Inc, Illinois.

Kurien Prem a 2002, Kaleidoscopic Ethnicity: International Migration and the Reconstruction of Community Identities in India, Rutgers University Press, New York.

Malla y a L k sh m a a 2016, Mahajan. The Konkani Culture, Lustre and Heritage, n.d., Cochin.

Man i B raj R a n a n 2005, Debrahmanising History: Dominance and Resistance in Indian Society, Manohar Publishers \& Distributors, n.d.

Maye r Adrian 1996, Caste in Contemporary India: Change and Continuity 1954-1992, [in:] Ch. Fuller (ed.), Caste Today, Oxford University Press, Delhi, pp. 32-64.

M in e s Mat t is on 1984, The Warrior Merchants. Textiles, Trade and Territory in South India, Cambridge University Press, Cambridge.

Mulle r Max 1869, Chips From a German Workshop, Charles Scribner \& Co, New York.

$\mathrm{Natrajan} \mathrm{B} \mathrm{lmurli} \mathrm{2005,} \mathrm{Caste,} \mathrm{Class} \mathrm{and} \mathrm{Community} \mathrm{in} \mathrm{India:} \mathrm{An} \mathrm{Ethnographic} \mathrm{Approach,}$ Ethnology, Vol. 44, No. 3, pp. 227-241.

Natrajan B almurli 2012a, From Jati to Samaj, Seminar (Delhi, India), Vol.633, pp. 54-57.

$\mathrm{N}$ at $\mathrm{r}$ a $\mathrm{j}$ a $\mathrm{B}$ a l m u rl i 2012b, The Culturalization of Caste in India: Identity and Inequality in a Multicultural Age, Routledge, New York.

P h a d $\mathrm{n}$ is U r mila 1990, Ethnicity and Nation Building in South Asia, Sage Publications, New Delhi.

Reddy Deep a 2005, The Ethnicity of Caste, Anthropological Quarterly, Vol. 78, no. 3, pp. 543-584.

Priy a A r y a 2016, Ethnicity in Post-Independent India: A Sociological Perspective on Its Causes and Manifestations, IOSR Journal Of Humanities And Social Science, Vol. 21, no. 1, ver. 5 (Jan. 2016), pp. 56-61.

Sadasivan Sivan and a mandiram Narayanan 2000, A Social History of India, APH Publishing, New Delhi.

S c h e r m e r h o r n R. A. 1978, Ethnic Plurality in India, University of Arizona Press, Tucson.

S h e th D. L. 1999, Secularisation of Caste and Making of New Middle Class, Economic and Political Weekly, Vol. 34 (34/35), pp. 2502-2510.

Srinivas Mysore Narasim a char 1952, Religion and Society Among the Coorgs of South India, Oxford at the Clarendon Press, London.

V o i c e s... 2013, Voices of Fort Kochi/Mattancherry, (ed.) Meena Divakar, n.d., Cochin.

\section{ALINA KACZMAREK-SUBRAMANIAN}

\section{CASTE AND ETHNICITY IN SOUTH INDIA: A CASE STUDY OF THE KONKANI PEOPLE IN KOCHI}

Key words: India, caste, ethnicity, ethnicization, social practice, Asian studies, Kochi

This article attempts to present the problem of caste and ethnicity in the 2010s based on anthropological and sociological insights applicable to the case study of the Konkani people who inhabit the city of Kochi in southern India. Applying the theory of ethnicity (Natrajan, Reddy) and ethnographic inquiry, the article investigates the question of how in the democratic state of India, having officially abolished the caste system moe than 70 years ago, the caste situation really looks and how it overlaps 
with newer identity formations such as ethnicity. Though the framework of caste has been changed, it still can be found in new forms. One of those niches is the Konkani community in he urban environment of Kochi. This paper portrays current ways of cultivating caste in the reality of a democratic state, where the traditional caste system interweaves with the broader national, ethnic, educational, and economic awarenesses, which are of an entirely different nature.

A. K.-S.

Author's Address:

Mgr Alina Kaczmarek-Subramanian

Institute of Archeology and Ethnology, Polish Academy of Sciences

Al. Solidarności 105, 00-140 Warsaw, Poland

E-mail: alina.z.kaczmarek@gmail.com

ORCID: 0000-0002-2317-8536 